\title{
Frontotemporal Dementia and Parkinsonism Linked to Chromosome 17: A Consensus Conference
}

\author{
Norman L. Foster, MD, ${ }^{*}$ Kirk Wilhelmsen, MD, PhD, $\dagger$ Anders A. F. Sima, MD, PhD, $\neq \$$ \\ Margaret Z. Jones, MD, Constance J. D’Amato, BS, $\neq$ Sid Gilman, MD, ${ }^{*}$ and Conference Participants
}

\begin{abstract}
We held an international consensus conference on frontotemporal dementia, behavioral disturbances, and parkinsonism linked to chromosome 17 to determine whether these are homogeneous or heterogeneous disorders, to agree on terminology, and to develop strategies for further research. The group identified 13 kindreds with sufficient evidence for linkage, finding in common to all a critical $2 \mathrm{cM}$ between markers D17S791 and D17S800. There was agreement that (1) despite previous descriptions that have emphasized one or another clinical or neuropathological feature, the kindreds share clinical and neuropathological features; (2) until more specific information about the genetic defects becomes available, this disorder is best termed frontotemporal dementia and parkinsonism linked to chromosome 17; and (3) further research will be enhanced by identifying the gene or genes responsible for this disorder, detecting additional cases within known families and, in new families, correlating mutations with phenotypes and more fully delineating the clinical, neuropsychological, and neuropathological characteristics of this disorder.
\end{abstract}

Foster NL, Wilhelmsen K, Sima AAF, Jones MZ, D'Amato CJ, Gilman S, Conference Participants. Frontotemporal dementia and parkinsonism linked to chromosome 17: a consensus conference. Ann Neurol 1997;41:706-715

Most dementia in late life is caused by Alzheimer's disease (AD), but neuropathological examinations sometimes disclose other neurodegenerative disorders. In approximately 3 to $10 \%$ of these patients, autopsy fails to reveal the characteristic neuropathological features of the common causes of dementia, including $\mathrm{AD}$, stroke, structural lesions, Parkinson's disease, diffuse Lewy body disease, or Pick's disease $[1,2]$. The terminology to describe such cases varies and many names have been used. Nonspecific dementia is the most commonly used term, but dementia lacking distinctive histology, Pick's disease without Pick bodies, and frontotemporal dementia [2-6] are terms that have also been used. These dementias have been difficult to study because the clinical variability makes it unclear whether they represent a distinct clinical syndrome. Many patients later found to have one of these dementias were erroneously thought to have $\mathrm{AD}$, but in some cases atypical features were recognized $[7,8]$.

Many patients with nonspecific neuropathology or frontotemporal dementia have a disease that is hereditary, up to $60 \%$ in one series $[1,3,9,10]$. Recently, dementia in 1 such family was linked to chromosome
17 [11]. Subsequently, several other families have had difficult-to-classify, progressive neurodegenerative disorders that have been linked to the same region of chromosome 17. Because these families have been considered in isolation, their disorders have received various names that emphasize particular clinical or neuropathological features. This has made the disorders appear disparate when they in fact may have much in common.

To extend our knowledge about chromosome 17linked dementia, a forum was needed to bring together investigators who could compare the clinical and neuropathological features of the disorders in identified kindreds, determine whether they share common elements, develop a consensus about these issues, and formulate strategies for further research.

\section{Methods \\ An international consensus conference was held in Ann Ar- bor, Michigan, October 4 through 6, 1996. Before the meet- ing, the organizing committee searched the medical literature to identify all known kindreds with a neurodegenerative dis- ease linked to chromosome 17. We contacted investigators}

From the Departments of *Neurology and $\ddagger$ Pathology, University of Michigan, Ann Arbor, $\$$ Departments of Parhology and Neurology, Wayne State University, Detroit, and Department of Pathology, Michigan State University, East Lansing, MI; and †Department of Neurology, University of California, San Francisco, San Francisco, CA.

See page 714 for conference participants.
Received Nov 7, 1996, and in revised form Feb 4 and Mar 6, 1997. Accepted for publication Mar 7, 1997.

Address correspondence to Dr Foster, Department of Neurology, University of Michigan Medical Center, 1920 Taubman Center, Box 0316, Ann Arbor, MI 48109-0316. 
who were familiar with each kindred and invited them to attend the meeting and to present clinical, genetic, and neuropathological data. They were also asked to identify any other kindreds that have been linked to chromosome 17 . We gave the investigators a list of publications related to their kindreds that they checked for accuracy and completeness. We distributed a list of key published references to all participants for review before the meeting. The conference included clinicians, geneticists, and neuropathologists associated with each kindred and an independent panel of senior commentators with expertise in dementia and neurodegenerative disorders. These commentators provided perspective and a summary of each day's deliberations.

At the beginning of the meeting, the organizing committee instructed participants on procedures for achieving consensus, and the moderators used previously described methods to encourage consensus among all participants [12]. In a plenary session on the first day, the invited participants presented the clinical, laboratory, neuropathological, and genetic features of each kindred showing linkage to chromosome 17 and cases of sporadic and familial neurodegenerative disorders that clinically and neuropathologically resemble the described kindreds but are not known to be linked to chromosome 17. On the second day, clinicians, neuropathologists, and geneticists held three discipline-specific sessions to present and discuss in detail the characteristics of the kindreds and to address a list of predetermined questions. In a final plenary session on the third day, the conclusions of the discipline-specific sessions were presented and discussed and the participants agreed on a final consensus statement.
The conference-organizing committee provided a draft consensus statement in advance of the meeting to guide the discussions. The participants reviewed the statement and modified both the statement and the tables summarizing information presented at the meeting. Members of the organizing committee served as moderators of the disciplinespecific sessions and recorded the results of the consensus.

\section{Results}

Kindreds with Frontotemporal Dementia and Parkinsonism Linked to Chromosome 17

The participants discussed 25 families they had identified. They agreed that 8 families have disease that is definitely linked to the critical region of chromosome 17 because of multipoint affected-only LOD scores greater than 3, and they classified 5 families as having disease that is probably linked because of LOD scores between 1 and 3 (Table 1). The remaining 12 kindreds had similar clinical and neuropathological features but had only a small number of available tissue samples for DNA testing. In these kindreds where LOD scores were less than 1, there was no indication of a genetic mutation at another location, but linkage to chromosome 17 had to be classified as uncertain. Information about these kindreds was tabulated, but they were otherwise not considered further in the deliberations.

The 13 families with definitely and probably linked disease have been analyzed by a subset of markers that

Table 1. Kindreds with Neurodegenerative Disease Linked to Chromosome 17

\begin{tabular}{|c|c|c|c|c|}
\hline & Number in Pedigree & $\begin{array}{l}\text { Affected Only } \\
\text { Multipoint } \\
\text { LOD Score }\end{array}$ & Flanking Markers & References \\
\hline \multicolumn{5}{|l|}{ Definitely linked } \\
\hline Irish family 1 (family $\mathrm{Mo}$ ) & 13 of 33 in 3 generations & $>3$ & D17S798-D17S808 & $11,20-22$ \\
\hline $\begin{array}{l}\text { Pallido-ponto-nigral de- } \\
\text { generation (PPND) }\end{array}$ & 35 of 303 in 8 generations & 6.8 & D17S250-D17S943 & $23-29$ \\
\hline $\begin{array}{l}\text { Familial multiple system } \\
\tau \text {-opathy with presenile } \\
\text { dementia (FMST) }\end{array}$ & 41 of 383 in 6 generations & $>3$ & THRA1-D17S791 & None \\
\hline Seattle family A or BK & 18 of $\sim 60$ in 3 generations & $>3$ & No obligate recombinants & 30,31 \\
\hline Dutch family I & 49 of 162 in 6 generations & $>3$ & D17S800-D17S790 & 32 \\
\hline $\begin{array}{l}\text { Duke University family } \\
1684\end{array}$ & 16 of 41 in 5 generations & $>5$ & D17S800-D17S806 & 33 \\
\hline $\begin{array}{l}\text { Hereditary dyphasic disin- } \\
\text { hibition dementia } \\
\text { (HDDD) family } 2\end{array}$ & 21 of 475 in 8 generations & 3.7 & No obligate recombinants & 34 \\
\hline Australian family & 26 of 172 in 5 generations & $>3$ & No obligate recombinants & 35,36 \\
\hline \multicolumn{5}{|l|}{ Probably linked } \\
\hline Dutch family II & 34 of 144 in 7 generations & 1.6 & No obligate recombinants & $15,37-40$ \\
\hline Dutch family III & 30 of 169 in 5 generations & 2.6 & $\mathrm{D} 17 S 953^{\mathrm{a}}-\mathrm{D} 17 \mathrm{~S} 791$ & 32 \\
\hline Karolinska family & 12 of 35 in 5 generations & 2.7 & No obligate recombinants & None \\
\hline $\begin{array}{l}\text { Familial progressive subcor- } \\
\text { tical gliosis (FPSG), fam- } \\
\text { ily A }\end{array}$ & 17 of 67 in 5 generations & 1.6 & No obligate recombinants & 19,41 \\
\hline Seattle family B & 7 of 30 in 3 generations & 1.1 & No obligate recombinants & None \\
\hline
\end{tabular}

${ }^{a}$ Nonrecombinant marker. 
have been ordered in publicly available meiotic segregation maps (http://www.genethon.fr/genethon_en. html, http://www.chlc.org/) allowing direct comparison of linkage data. The presence of disease in these families segregates with markers in the $17 \mathrm{q} 21-22$ region, which includes, in all kindreds, a critical $2 \mathrm{cM}$ between markers D17S791 and D17S800 (Fig). Linkage analysis used to classify kindreds was based on an "affected-only model" because the age-adjusted penetrance varies between families. In this model, marker data are used for all available family members and the clinical phenotypes for unaffected individuals are treated as unknowns.

At least 4 families have been described that have clinical and neuropathological features similar to those in families with linkage to $17 \mathrm{q} 21-22$, but linkage studies have excluded this region [13]. One of these families has disease that is linked to chromosome 3 , and the others have not yet been determined [14].

In addition to evaluation for disease with linkage to $17 q 21-22$, many of the families have been examined for segregation with or mutations in other loci that are associated with neurodegeneration such as the genes for amyloid precursor protein, prion protein, presenilin 1, and presenilin 2. Direct sequence analysis and mutation screening have not revealed mutations that can be inferred to affect disease susceptibility in these genes. Insufficient data are available to determine whether other loci modulate the expression of mutations in the 17q21-22 locus.

\section{Clinical Features in Kindreds with. Disease Linked to Chromosome 17}

Although some clinical features differ within kindreds and between kindreds, we found many features in common among affected individuals in the kindreds in which linkage to chromosome 17 has been demonstrated. The disease commonly begins insidiously with behavioral or motor manifestations, typically in the fifth decade and occasionally in the third, fourth, or sixth decade. The duration of the disease is variable, usually extending 10 years, but it can be as short as 3 years and as long as 30 years. Patients may first seek medical attention because of cognitive impairment progressing to dementia, parkinsonism, nonfluent aphasia, a change in personality, or psychosis. The principal clinical features consist of behavioral, cognitive, and motor disturbances (Table 2). These include impaired social conduct ranging from aggressiveness to apathy; hyperorality; hyperphagia; obsessive stereotyped behavior; psychosis, including delusions, paranoid ideation, and hallucinations; diminished speech output progressing to muteness; and a progressive frontotemporal dementia. It is noteworthy that neuropsychological examinations show disturbed executive function, whereas visuospatial function, orientation, and memory are relatively preserved until late in the illness. The clinical features are distinct from those of $\mathrm{AD}$ where memory and cognitive decline predominate. The motor abnormalities consist principally of parkinsonian extrapyramidal disorders with bradykinesia, rigidity, and postural instability, but without resting tremor. Corticospinal disturbances, muscle wasting, and fasciculations are seen in a minority of the cases. No significant benefit was observed with levodopa when it was tried. Supranuclear ophthalmoplegia and apraxia of eyelid opening is sometimes observed. Autonomic function is spared, at least early, and incontinence of both bladder and bowel occurs late in the course as dementia becomes increasingly severe. Changes in body weight may

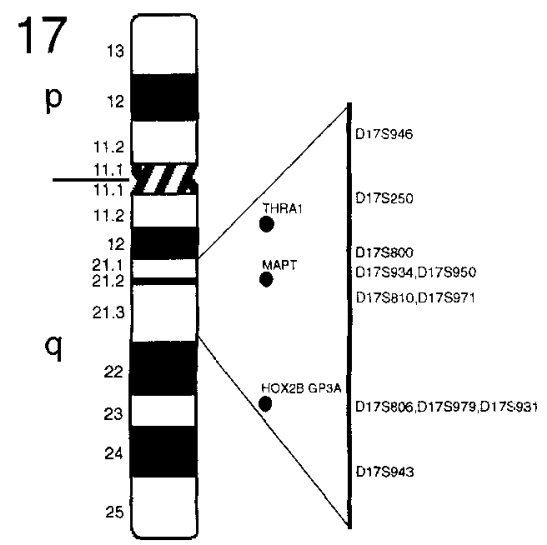

A

B

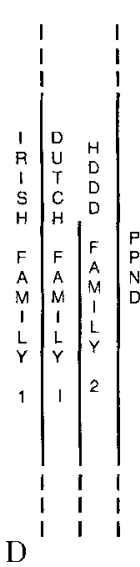

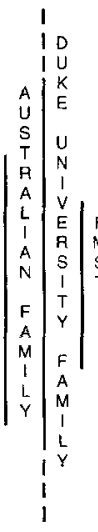

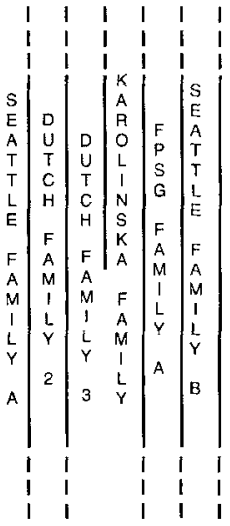

Fig. Linkage analysis for frontotemporal dementia and parkinsonism linked to chromosome 17 (FTDP-17) families. (A) The location of the FTDP-17 locus is shown on an ideogram of a metaphase chromosome. The relative locations of gene loci and marker loci in the $17 q 21 \mathrm{re}$ gion are shown in $B$ and $C$. (B) Gene loci have been positioned by meiotic segregation analysis and radiation hybrid somatic cell breakpoint analysis (Genome database, Welch Library, Johns Hopkins University; Wilhelmsen $K$, Clark L, unpublished data). (C) The locations of genetic markers shown are based on the 1996 Genethon map and are not drawn to scale. Next to each family identification is a line that indicates the probable location of the disease gene for that family. (D) Dashed lines indicate that the disease gene could be in a region that extends beyond the map shown in $C$. 
Behavioral disturbances

Disinhibition: socially inappropriate behavior, including undue familiarity, and flamboyance in words and dress

Apathy, remoteness and social isolation, depressed mood

Defective judgment as in faulty financial decisions and unsafe driving habits

Poor impulse control

Repetitive, stereotypic, compulsive behavior, hyperreligiosity

Psychosis with visual and auditory hallucinations, delusions and paranoia

Alcoholism

Verbal and physical aggressiveness

Hyperorality with hyperphagia, including consumption of nonfood objects

Early loss of personal awareness and neglect of personal hygiene

Cognitive disturbances

Early manifestations

Relative preservation of memory, orientation, and visuospatial functions

Speech disturbances with nonfluent aphasia

Disorders of executive function: impaired set shifting, mental flexibility, foresight and planning

Subsequent manifestations

Progressive deterioration of memory, orientation, and visuospatial functions

Echolalia, perseveration, and palilalia increasing to mutism

Progressive dementia

Motor disturbances

Commonly observed

Extrapyramidal disorders with parkinsonian manifestations appearing early or late in the course, characterized by bradykinesia, axial and limb rigidity, postural instability, without resting tremor, unresponsive to levodopa therapy in the kindreds studied

Corticospinal disturbances with hyperreflexia, clonus, extensor plantar responses

Occasionally observed

Axial and limb dystonia including retrocollis, myoclonus, and adventitial movements such as choreas, postural and action tremors

Loss of voluntary eyelid opening

Oculomotor disorders, including slowed saccades and supranuclear palsy

Late onset of dysphagia and dysarthria

Late onset of muscle wasting and fasciculation

occur, including increases in association with hyperphagia early in the course and decreases late in the disease, the latter often resulting from dysphagia. Epileptic seizures are rare but may occur late in the disease course. In contrast to those performed in patients with some other dementias, electroencephalographic (EEG) studies are often normal until late in the disease. Structural imaging studies may show frontotemporal atrophy that sometimes is asymmetric. Available functional imaging studies are compatible with the clinical presentation, showing frontal and anterior temporal hypoperfusion or hypometabolism in a pattern different from that typically seen in $\mathrm{AD}$, loss of presynaptic dopaminergic markers, and upregulation of striatal dopaminergic receptors.

The clinical features within a single kindred are often similar but not identical. The variability of clinical features within members of the same family indicates that environmental and other genetic factors may modify the clinical expression of these disorders.

Affected individuals in families with probable linkage are similar to those in families with definite linkage to chromosome 17 . We were unable to identify any features that reliably distinguish linked families from families known not to be linked to chromosome 17 or a family with a clinically and neuropathologically similar disorder linked to chromosome 3 [14].

Neuropathological Features in Kindreds with Disease Linked to Chromosome 17

Frontotemporal atrophy is a consistent feature, and basal ganglia atrophy and substantia nigra depigmentation are found in most kindreds (Table 3). Hemispheric atrophy is asymmetric in only 3 families with disease of probable linkage to chromosome 17 .

Microscopic examination consistently reveals neuronal loss, neuropil vacuolation of the superficial layers of the cerebral cortex, and gliosis in both gray and white matter of variable intensity (Table 4). In 4 kindreds (Irish family 1, pallido-ponto-nigral degeneration, familial multiple system $\tau$-opathy, and familial progressive subcortical gliosis family $\mathrm{A}$ ), argyrophilic and/or $\tau$-positive neuronal inclusions without the characteristics of Pick bodies, argyrophilic and/or $\tau$-positive glial inclusions, and ballooned neurons are found in all cases examined. One kindred (Seattle family A) shows this $\tau$-positive neuronal pathology alone. Another 4 kindreds (hereditary dysphasic disinhibition dementia 
Table 3. Gross Brain Neuropathology in Kindreds with Disease Linked to Chromosome 17

\begin{tabular}{|c|c|c|c|c|c|c|}
\hline & $\begin{array}{l}\text { No. of } \\
\text { Cases }\end{array}$ & $\begin{array}{l}\text { Brain Weight } \\
\text { (g) }\end{array}$ & $\begin{array}{l}\text { Asymmetric } \\
\text { Atrophy }\end{array}$ & $\begin{array}{l}\text { Distribution of } \\
\text { Atrophy }\end{array}$ & $\begin{array}{l}\text { Basal Ganglia } \\
\text { Atrophy }\end{array}$ & $\begin{array}{l}\text { Substantia Nigra } \\
\text { Depigmentation }\end{array}$ \\
\hline \multicolumn{7}{|c|}{ Definitely linked } \\
\hline Irish 1 & 6 & $970-1,350$ & 0 & $\begin{array}{l}\text { Frontotemporal anterior } \\
\text { cingulate }\end{array}$ & + & + \\
\hline PPND & 12 & $\mathrm{~N} / \mathrm{A}$ & 0 & Frontotemporal & + & + \\
\hline FMST & N/A & $N / A$ & 0 & Frontotemporal & + & + \\
\hline Seattle A & 5 & $870-1,200$ & 0 & Frontotemporalparietal & 0 & 0 \\
\hline Dutch I & 14 & $855-1,230$ & 2 & Frontotemporal & + & $4 / 14$ \\
\hline Duke 1684 & 3 & 990 & 0 & Frontotemporal & + & + \\
\hline HDDD2 & 4 & $740-1,340$ & 0 & Frontoparietal & + & + \\
\hline Australian & 4 & N/A & $\mathrm{N} / \mathrm{A}$ & Frontotemporal & $\mathrm{N} / \mathrm{A}$ & $\mathrm{N} / \mathrm{A}$ \\
\hline \multicolumn{7}{|c|}{ Probably linked } \\
\hline Dutch II & 15 & $730-1,250$ & 2 & Frontotemporal & + & $4 / 15$ \\
\hline Dutch III & 1 & 1,170 & 0 & Frontotemporal & + & + \\
\hline Karolinska & 3 & $935-1,440$ & + & Frontotemporal & + & + \\
\hline FPSG, A & 5 & $850-1,040$ & 0 & Frontotemporal & + & + \\
\hline Seattle B & 4 & $\mathrm{~N} / \mathrm{A}$ & + & Frontotemporal & + & + \\
\hline
\end{tabular}

PPND $=$ pallido-ponto-nigral degeneration; FMST $=$ familial multiple system $\tau$-opathy with presenile dementia; HDDD2 $=$ hereditary dyphasic disinhibition dementia family 2; FPSG, $A=$ familial progressive subcortical gliosis, family $\mathrm{A} ; \mathrm{N} / \mathrm{A}=$ data not available; $+=$ present; $0=$ absent.

Table 4. Microscopic Neuropathology by Kindreds with Disease Linked to Chromosome 17

\begin{tabular}{|c|c|c|c|c|c|c|c|}
\hline & $\begin{array}{l}\text { Neuronal } \\
\text { Loss }\end{array}$ & $\begin{array}{l}\text { Gray Matter } \\
\text { Gliosis }\end{array}$ & $\begin{array}{l}\text { Neuronal Inclusions } \\
\text { (Argyrophilic } \\
\text { and/or } \tau+\text { ) }\end{array}$ & $\begin{array}{l}\text { Glial Inclusions } \\
\text { (Argyrophilic } \\
\text { and/or } \tau+\text { ) }\end{array}$ & $\begin{array}{l}\text { Ballooned } \\
\text { Cells }\end{array}$ & $\begin{array}{l}\text { Neuropil } \\
\text { Vacuolation }\end{array}$ & $\begin{array}{l}\text { White Matter } \\
\text { Gliosis }\end{array}$ \\
\hline \multicolumn{8}{|c|}{ Definitely linked } \\
\hline Irish 1 & + & + & + & + & + & + & + \\
\hline PPND & + & + & + & + & + & 0 & + \\
\hline FMST & + & + & + & + & + & + & + \\
\hline Seattle A & + & + & + & 0 & N/A & $\mathrm{N} / \mathrm{A}$ & $N / A$ \\
\hline Dutch I & + & + & 0 & 0 & $0 /+$ & + & + \\
\hline Duke 1684 & + & + & 0 & 0 & 0 & + & + \\
\hline HDDD2 & + & + & N/A & $\mathrm{N} / \mathrm{A}$ & + & + & N/A \\
\hline Australian & + & + & 0 & 0 & + & + & N/A \\
\hline \multicolumn{8}{|l|}{ Probably linked } \\
\hline Dutch II & + & + & 0 & 0 & $0 /+$ & + & + \\
\hline Dutch III & + & + & 0 & 0 & 0 & + & + \\
\hline Karolinska & + & + & 0 & 0 & 0 & + & + \\
\hline FPSG, A & + & + & + & + & + & + & + \\
\hline Seattle B & + & + & 0 & 0 & 0 & + & N/A \\
\hline
\end{tabular}

PPND = pallido-ponto-nigral degeneration; FMST = familial multiple system $\tau$-opathy with presenile dementia; HDDD2 $=$ hereditary dyphasic disinhibition dementia family 2; FPSG, $\mathrm{A}=$ familial progressive subcortical gliosis, family $\mathrm{A} ; \mathrm{N} / \mathrm{A}=$ data not available; $+=$ present; $0=$ absent.

family 2, the Australian family, Dutch family I, and Dutch family II) show ballooned neurons without associated $\tau$ pathology, and the remaining 4 kindreds lack both abnormalities. These features can be used to subdivide the kindreds into the following 4 groups: $\tau$ and ballooned neuron positive; $\tau$-positive alone; ballooned neuron positive alone; and ballooned neuron negative. Because varying techniques have been used in evaluating $\tau$ pathology, this classification is only tentative. At present, it is the substantial similarities rather than these histological distinctions between kindreds that remain most remarkable.

Semiquantitative regional histopathological examination reveals neuronal loss and gliosis that is most severe in the frontal and temporal cortices, accompanied by neuronal loss and gliosis in the substantia nigra (Table 5). In most cases, neurons of the hippocampal formation are preserved. Neuronal loss with degenerative changes is moderate in the basal ganglia. Neuronal loss and gliosis of the amygdala is severe, except in 3 kin- 
Table 5. Semiquantitative Regional Neuropathology in Kindreds with Disease Linked to Chromosome 17

\begin{tabular}{|c|c|c|c|c|c|c|c|c|c|c|c|}
\hline & Frontal & Temporal & Cingulate & Parietal & $\begin{array}{l}\text { Hippo- } \\
\text { campus }\end{array}$ & Amygdala & Basal Ganglia & Thalamus & $\begin{array}{l}\text { Substantia } \\
\text { Nigra } \\
\text { Mesen- } \\
\text { cephalon }\end{array}$ & $\begin{array}{l}\text { Motor } \\
\text { System }\end{array}$ & Pons \\
\hline \multicolumn{12}{|c|}{ Definitely linked } \\
\hline Irish 1 & $++^{a, b}$ & $++^{a \cdot b}$ & $++^{b}$ & 0 & + & $+++^{b}$ & ++ & + & $+++^{a}$ & + & $t^{a}$ \\
\hline PPND & $+^{a, b}$ & $++^{\mathrm{a}, \mathrm{b}}$ & $++^{a, b}$ & $+^{a, b}$ & $++^{a}$ & $+++^{a, b}$ & $++/+++a, b$ & $++^{a}$ & $+++a$ & $+a$ & +3 \\
\hline FMST & $+1+++^{\mathrm{a}, \mathrm{b}}$ & $+1++t^{a}$ & $+1+++i$ & $+1++^{a}$ & $+1++^{a}$ & $+1+++^{a}$ & $+1+++^{a}$ & $+^{a}$ & $+1+++^{a}$ & $+1++^{a}$ & $+1++^{4}$ \\
\hline Dutch I & $++1++t^{b}$ & $+++^{b}$ & +++ & + & + & + & ++ & ++ & + & $N / A$ & + \\
\hline Duke 1 & + & ++ & + & 0 & 0 & + & ++ & 0 & +++ & + & ++ \\
\hline HDDD2 & $++1+++$ & $+1++$ & $\mathrm{N} / \mathrm{A}$ & $++1+++$ & $+1++$ & $0 /++{ }^{b}$ & $++1+++$ & $+1++$ & + & 0 & 0 \\
\hline Australian & $++^{\mathrm{b}}$ & $++^{\mathrm{b}}$ & N/A & N/A & 0 & N/A & $\mathrm{N} / \mathrm{A}$ & N/A & ++ & $\mathrm{N} / \mathrm{A}$ & 0 \\
\hline \multicolumn{12}{|c|}{ Probably linked } \\
\hline Dutch II & $+++^{b}$ & $+++^{b}$ & +++ & + & ++ & ++ & ++ & ++ & 0 & N/A & ++ \\
\hline Dutch III & ++ & ++ & +++ & ++ & ++ & ++ & $+1++$ & $+1++$ & + & N/A & + \\
\hline Karolinska & +++ & ++ & ++ & + & + & + & + & + & + & 0 & 0 \\
\hline Seattle B & +++ & +++ & +++ & $\mathrm{N} / \mathrm{A}$ & +++ & +++ & +++ & $N / A$ & +++ & N/A & N/A \\
\hline
\end{tabular}

a-Positive cytoplasmic inclusions.

'Ballooned neurons.

PPND = pallido-ponto-nigral degeneration; FMST $=$ familial multiple system $\tau$-opathy with presenile dementia; HDDD2 = hereditary dyphasic disinhibition dementia family 2; FPSG, $\mathrm{A}=$ familial progressive subcortical gliosis, family $\mathrm{A} ; 0=$ absent; $+=$ mild; $++=$ moderate; $+++=$ severe; $\mathrm{N} / \mathrm{A}=$ data not available.

dreds showing only mild changes. Motor neuron involvement was identified in 4 kindreds, consisting of degenerative changes of the motor cortex and/or motor neurons of the brainstem or spinal cord. Two patients in a family with definitely linked disease (Seattle family

A) had excessive numbers of $\beta$-amyloid plaques.

No differences are found between families with definitely linked and probably linked disease, in the distribution or severity of cortical neuronal loss and gliosis, basal ganglia pathology, or severity of depigmentation and neuronal loss in the substantia nigra. Argyrophilic and $\tau$-positive inclusions are not found in any cases of the families with disease of probable linkage. Diffuse Lewy bodies, amyloid deposition, and Pick bodies exceeding those expected for age are not found in any of the families with definitely or probably linked disease. Neuritic plaques excessive in number for age are seen only in rare cases.

\section{Discussion}

The highest priority in advancing knowledge of chromosome 17-linked neurodegenerative disease is to characterize the gene or genes responsible. Identification of a gene is inevitable, but the search may be protracted. Progress in our understanding will be aided by collaboration to share genetic information, identify additional kindreds, and characterize more fully the clinical, neuropsychological, and neuropathological features of this disease.

\section{Classification of Kindreds}

Clear commonalities emerged in discussions of the clinical and neuropathological features of the kindreds with disease linked to chromosome $17 \mathrm{q} 21-22$. The predominant features included a severe behavioral dis- order characteristic of the frontotemporal dementias accompanied by a parkinsonian syndrome without resting tremor. Neuropathologically, the common features consisted of neuronal loss, gliosis, and spongiosis most severe in the frontal, temporal, and cingulate cortices, and neuronal loss in substantia nigra. Until the genetics of these kindreds is fully defined, it appears reasonable to consider them together.

Several sporadic disorders have frontotemporal dementia and parkinsonism similar to that seen in chromosome 17-linked kindreds. The sporadic cases we considered were those in which no other relatives appeared to be similarly affected after a careful review of their medical history and considering their age at the time of death. The relationship of the sporadic disorders to the hereditary disorders is unknown. Although there are similarities, none of the names applied to these sporadic disorders adequately describes all of the linked hereditary cases. Likewise, none of the names used to describe a single kindred is sufficiently inclusive or descriptive to be applied to all. We therefore agreed to a new nomenclature. Because the dominant features of the hereditary disorder consist of a frontotemporal dementia with parkinsonism, we adopted the term frontotemporal dementia and parkinsonism linked to chromosome 17 (FTDP-17).

\section{Need for Additional Clinical Studies}

Additional clinical examinations of affected individuals in identified kindreds are needed to assess the extent to which similar features are present in all. At present, analysis of kindreds is hindered by difficulty in making direct comparisons. The frequency of specific clinical findings cannot now be accurately determined because so few cases have been described and not all pertinent 
features have received comment. The frequency of clinical features also varies considerably during the illness, and longitudinal clinical observations are needed that note disease severity. Collaborations are encouraged for standardization of clinical data and performance of clinical studies presently available at only a few sites. A systematic review of available structural imaging studies would provide information about the utility of computed tomographic scanning and magnetic resonance imaging in recognizing the focal atrophic change uniformly identified by gross inspection at postmortem examination. In particular, neuropsychometric testing, standardized neuropsychiatric assessment, and functional brain imaging offer the possibility of distinguishing, before death, individuals with this disorder from those with familial AD. EEG findings appear unlikely to be sufficiently specific to aid in recognition of FTDP-17. Neuropathological findings suggest that measurement of cerebrospinal fluid $\tau$ levels may be informative, but this has not yet been studied in these kindreds. There is no evidence that apolipoprotein $\mathrm{E}$ genotype alters the expression of these disorders.

\section{Need for Additional Neuropathological Studies}

The distinctive combination and distribution of neuropathological findings identified in kindreds with disease linked to chromosome 17 will assist in the identification of suspected cases from available autopsy cases. The following four issues concerning the neuropathology of FTPD-17 emerged and should be evaluated further: (1) characterization of the abnormal $\tau$ protein to detect similarities between kindreds in which it was found; (2) evaluation of abnormalities in density and distribution of corrical synapses by using immunocytochemical and morphometric techniques; (3) determination of the laminar distribution of cortical pathology within affected regions; and (4) development of a protocol for consistent and appropriate handling of brains harvested from frontotemporal dementia cases, including sections, stains, and immunocytochemistry. To permit comparability between cases, sections from the following regions should be evaluated with hematoxylin and eosin stain, Bielschowsky stain, and $\tau$ protein immunocytochemistry: frontal cortex; temporal cortex; anterior cingulate gyrus; caudate nucleus, putamen, globus pallidus; amygdaloid nucleus; thalamus; hippocampus; midbrain with substantia nigra; pons; and cerebellar vermis and medulla. Collaborations are encouraged to assess the frequency and range of severity of neuropathological features in specific brain regions and their relationship to clinical symptoms.

\section{Need for Additional Genetic Studies}

The families with FTDP-17 conceivably could be distantly related to each other or to as yet unidentified families. This possibility can be assessed by searching for shared haplotypes that will provide clues to the more precise location of the susceptibility gene. A series of microsatellite polymorphisms that are recommended for haplotype comparison have been identified in the critical region between D17S791 and D17S800. Two Centre d'Etudes du Polymorphisme Humain (CEPH) reference subjects were agreed on for standardization of allele assignments (http://www.cephb.fr/cephgenethon-map.html). (Haplotypes and information concerning the markers and reference subjects chosen are posted on the World Wide Web, and the Internet address can be obtained from the authors. Haplotypes will be accepted from the scientific community and distributed anonymously using the web site.)

\section{Identification of Additional Cases}

It is important to find additional families with FTDP-17 and to identify new members of the existing families. Carefully assessed subjects with sporadic diseases similar to FTDP-17 may be helpful in screening candidate genes for mutations. Without additional subjects, we are unlikely to define further the disease susceptibility locus on $17 \mathrm{q} 21-22$. At present, the closest recombinants that define the region containing the disease susceptibility locus are $2 \mathrm{cM}$ apart. Additional kindreds can be identified by recognizing patients with typical clinical features and by postmortem examination. Information about the clinical and neuropathological features of this disorder should be disseminated widely among physicians. Physicians should encourage families to permit postmortem examination of patients with dementia and unusual behavioral and parkinsonian syndromes.

Clinicians should consider FTDP-17 when evaluating a broad array of patients. Suspect cases include any individual with the onset before age 65 years of a familial disorder characterized by either (1) a behavioral disorder suggesting frontotemporal pathology or a dementing disorder, especially if supported by neuropsychological studies showing difficulty with executive function or with functional imaging studies showing frontotemporal hypometabolism/perfusion; and/or (2) parkinsonism, especially if resting tremor is absent and the symptoms are nonresponsive to levodopa. Diagnostic labels applied to hereditary disorders not linked to genetic markers may be misleading. For example, the evidence that Pick's disease is sometimes hereditary is largely based on a Dutch kindred without Pick bodies reviewed at this conference and found to have features and linkage typical of FTDP-17 [15]. Familial progressive supranuclear palsy shares many clinical and neuropathological features with FTDP-17 and such kindreds might be related to those discussed here [16].

Families with 2 or more affected individuals (the 
proband and 1 or more first- or second-degree relatives) can provide information that will assist in furthering the localization of the disease gene. The family history should be explored carefully in any patient with a clinical or neuropathological profile similar to that described for FTDP-17, by questioning the affected individual, those who accompany the patient to the clinical examination, and several first- and second-degree relatives they identify. Consultation with a geneticist or genetic counselor can be helpful in thoroughly exploring the family history. Affected relatives may have dementia, parkinsonism, amyotrophy, schizophrenia, or schizoaffective disorder and may have a variety of diagnoses that do not appear similar to the proband. Careful review of all available evidence may be necessary to ascertain whether relatives are affected. Families with as few as 4 or 5 affected individuals can be sufficient to determine probable linkage to or exclusion from chromosome $17 \mathrm{q} 21-22$ (or other known linkages such as chromosome 3). Geneticists attending the consensus conference are willing to assist or refer clinicians to investigators interested in ascertaining families and collecting specimens (addresses and telephone numbers are included in the supplemental materials).

Clinicians caring for affected subjects should be cautious when interpreting genetic research data in discussions with these subjects and their families. Until the complete implications of inheriting specific mutations are known, only limited genetic counseling can be provided.

\section{Heterogeneity in FTDP-17}

Although kindreds showed many clinical and neuropathological features in common, noteworthy differences emerged. Asymmetric cerebral atrophy was found in 2 kindreds with prominent aphasia, although this and other speech/language disorders were prominent in many families. Further study of known affected individuals and identification of additional families will provide a more complete understanding of the clinical and neuropathological heterogeneity in FTDP-17. The available genetics data suggest that mutations of one or possibly a few genes on chromosome 17q21-22 account for FTDP-17. The following two genetic mechanisms could explain the heterogeneity in FTDP-17 kindreds: (1) allelic mutations in the same genes (allelic heterogeneity), and (2) mutations in different genes located on chromosome 17q21-22 (locus heterogeneity). Many of the affected families are large and geographically dispersed, and thus are likely to be influenced by heterogeneity of genetic background and diverse environmental exposures. Hence, it is unlikely that genetic background or environmental factors contribute importantly to the phenotypic differences between families. This notion is reinforced because the high penetrance of the clinical and neuropathological phe- notypes appear to cosegregate. We make these inferences cautiously because recent work with other disorders such as Machado-Joseph disease suggests that substantial clinical heterogeneity can occur within families with the same mutations [17].

\section{Prevalence of FTDP-17}

Inadequate information exists to determine the prevalence of FTDP-17; however, the number of identified kindreds is increasing rapidly as this condition is becoming more widely known. The number of families identified has doubled since planning for this conference began in October 1995. Identification of one or more genetic mutations will permit testing of individuals, which will help to determine the prevalence of this disorder. All currently identified affected individuals are of Northern European descent. Additional efforts should be made to identify hereditary frontotemporal dementia and parkinsonism in other ethnic groups and to determine whether there is a true geographic or ethnic risk. Epidemiological studies that include individuals in the fifth and sixth decades of life should include questions sensitive to identifying behavioral changes suggesting frontotemporal degeneration.

\section{Clues to the Pathogenesis of FTDP-17}

Both $\tau$ accumulation and ballooned neurons are common to several sporadic dementing disorders. Accumulation of $\tau$ protein may be important in the pathogenesis, because this protein is transcribed by the region of chromosome 17 thought to harbor the mutations responsible for this disease. Ballooned cells are common in various neurodegenerative diseases and are characteristic of corticobasal ganglionic degeneration [18].

One of the kindreds possibly linked to chromosome 17 demonstrated prion protein $(\mathrm{PrP})$ immunoreactivity in tissues and intermediate proteinase $\mathrm{K}$-resistant $\operatorname{PrP}$ [19]. During the consensus conference, no evidence was presented suggesting an association between $\operatorname{PrP}$ and FTDP-17. No mutation of the PrP gene has been identified, and linkage to the $\operatorname{PrP}$ site on chromosome 20 was excluded in this and other FTDP-17 kindreds. At present, the role played by $\operatorname{PrP}$ in this disease is under investigation (Gambetti $\mathrm{P}$, personal communication).

Note: Readers can obtain 31 pages of additional data presented at the conference from the National Auxiliary Publications Service, PO Box 3513, Grand Central Station, New York, NY 10163-3513. The information includes a list of all publications on chromosome 17-linked kindreds and related articles identified for the conference (including abstracts, dissertations, and submitted manuscripts), additional summary tables of kindreds with similar features but undetermined linkage, clinical characteristics of linked kindreds, laboratory studies that have been completed in linked kindreds, recom- 
mended neuropathological sections and stains for diagnosis of FTDP-17, and comparison with other neurodegenerative disorders. Request document no. 05391. Remit with your order (not under separate cover), in US funds only, \$11.05 for photocopies or $\$ 5.00$ for a microfiche. For addresses outside the United States and Canada, an additional $\$ 5.50$ for photocopies and $\$ 1.75$ for microfiche is charged for postage and shipping.

\section{Conference Participants}

N. L. Foster, MD, K. Wilhelmsen, MD, PhD, and A. A. F. Sima, MD, PhD, served as moderators for the clinical, genetics, and neuropathology discipline-specific sessions. They, with M. Z. Jones, MD, C. J. D'Amato, BS, and S. Gilman, $\mathrm{MD}$, served as the organizing and writing committee for this conference. Others attending the conference contributed extensively to the development of this report by making prepared remarks, contributing published and unpublished data, participating in group discussions, and developing and reviewing this statement. Those contributing to discussions and joining in this consensus are listed below. Those contributing data are indicated by an asterisk $\left(^{*}\right)$. Geneticists participating in the conference can assist or refer clinicians and are indicated by a dagger ( $\dagger$. Cambridge University. M. G. Spillantini, $\operatorname{PhD}^{*} \dagger$; Columbia University: T. Lynch, MRCPI, ${ }^{*}$ and R. P. Mayeux, MD; Duke University: P. C. Gaskell, Jr, PH-C, ${ }^{*}$ C. M. Hulette, MD, ${ }^{*}$ M. A. PericakVance, $\mathrm{PhD},{ }^{*} \dagger$ and K. A. Welsh-Bohmer, $\mathrm{PhD}^{*}$; Einstein College of Medicine: D. W. Dickson, MD; Erasmus University, Rotterdam, The Netherlands: P. Heutink, MD, ${ }^{* \dagger} \mathrm{J}$. Kros, $\mathrm{MD}^{*}$ and J. C. van Swieten, MD*; Free University, Amsterdam, The Netherlands: F. Arwert, $\mathrm{PhD}^{*} \dagger$; Indiana University: M. B. Ghetti, MD, ${ }^{*}$ and J. Murrell, PhD*广; Karolinska Institute: L. Lannfelt, MD, PhD*; Mayo Clinic, Jacksonville: M. Hutton, PhD*t; Michigan State University: M. Jones, MD; National Institutes of Health: C. H. Phelps, PhD (NIA), D. S. Snyder, PhD (NIA), and E. Oliver, PhD (NINDS); Oregon Health Sciences University: M. J. Ball, MD; University of California, Los Angeles: J. L. Cummings, MD, and B. L. Miller, MD*; University of California, San Diego: R. Katzman, MD; University of California, San Francisco: K. Wilhelmsen, MD, $\mathrm{PhD}^{*}+$; University of lowa: L. Reed, $\mathrm{MD},{ }^{*}$ and R. L. Schelper, MD, PhD*; University of Kentucky: D. J. Lanska, MD, MS*; University Hospital, Lund, Sweden: A. Brun, MD*; University of Michigan: C. J. D’Amato, BS, J. K. Fink, MD, $\uparrow$ N. L. Foster, MD, ${ }^{*}$ S. Gilman, MD, and D. E. Kuhl; University of Minnesota: D. S. Knopman, MD*; University of Nebraska: Z. Wszolek, MD*; University of Southern California: C. A. Miller; University of Washington: T. D. Bird, $\mathrm{MD}^{* \dagger}$; Washington University: C. Lendon, $\mathrm{PhD}^{*}+$; Wayne State University: C. Elechi, MBBS, and A. A. F. Sima, MD, PhD.*

The conference was supported by NIH grant AG13904, the John Douglas French Alzheimer's Foundation, and the Michigan Alzheimer's Disease Research Center (NIH grant AG08671). Leco Corporation/Olympus America provided the microscope, camera, and video system used for group review of neuropathological specimens during the conference.
Sara Holmes, MPH, developed the consensus training materials and served as conference coordinator. We thank Margaret Allen, Judith L. Heidebrink, MD, Al Golden, and Kim. Forde for assistance with conference arrangements.

\section{References}

1. Brun A. Frontal lobe degeneration of non-Alzheimer type. I. Neuropathology. Arch Gerontol Geriatr 1987;6:193-208

2. Knopman DS, Mastri AR, Frey WH, et al. Dementia lacking distinctive histologic features: a common non-Alzheimer degenerative dementia. Neurology 1990;40:251-256

3. Kim RC, Collins GH, Parisi JE, et al. Familial dementia of adult onset with parhological findings of "non-specific" nature. Brain 1981;104:61-78

4. Knopman DS. Overview of dementia lacking distinctive histology: pathological designation of a progressive dementia. Dementia 1993;4:132-136

5. Clark AW, White CL, Sima AAF, et al. Primary degenerative dementia without Alzheimer pathology. Can I Neurol Sci 1986; 13(suppl 4):462-470

6. The Lund and Manchester Groups. Clinical and neuropathological criteria for frontotemporal dementia. J Neurol Neurosurg Psychiatry 1994;57:416-418

7. Gearing M, Mirra SS, Hedreen JC, ct al. The Consortium to Establish a Registry for Alzheimer's Disease (CERAD). Part X. Neuropathology confirmation of the clinical diagnosis of Alzheimer's disease. Neurology 1995;45:461-466

8. Mendez MF, Underwood KL, Zander BA, et al. Risk factors in Alzheimer's disease: a clinicopathologic study. Neurology 1992; 42:770-775

9. Schaumburg HH, Suzuki K. Non-specific familial presenile dementia. J Neurol Neutosurg Psychiatry 1968;31:479-486

10. Gustafson L. Clinical picture of frontal lobe degeneration of non-Alzheimer type. Dementia 1993:4:143-148

11. Wilhelmsen KC, Lynch T, Pavlou E, et al. Localization of disinhibition-dementia-parkinsonism-amyotrophy complex to 17q21-22. Am J Hum Genet 1994;55:1159-1165

12. Johnson DW, Johnson FP. Joining together: group theory and group skills. 5th ed. Boston: Allyn and Bacon, 1994

13. Gasser T, Wilhelmsen KC, Wszolek ZK. Familial parkinsonism: families $\mathrm{A}, \mathrm{B}$, and $\mathrm{C}$ are not linked to the wld locus on chromosome 17q21-22. Mov Disord 1996;11(suppl 1):166

14. Brown J, Ashworth A, Gydesen S, et al. Familial non-specific dementia maps to chromosome 3. Hum Mol Genet 1995;4: $1625-1628$

15. Groen JJ, Endtz LJ. Hereditary Pick's disease: second reexamination of the large family and discussion of other hereditary cases, with particular reference to electroencephalography, a computerized tomography. Brain 1982;105:443-459

16. de Yebenes JG, Sarasa JL, Daniel SE, Lees AJ. Familial progressive supranuclear palsy. Description of a pedigree and review of the literature. Brain 1995;118:1095-1103

17. Greenstein PE, Moore D, Levy-Lahad E, et al. Nine families with the SCA3/Machado-Joseph disease type of inherited ataxia. Neurology 1996;47:1106-1107

18. Mori $H$, Nishimura $M$, Namba $Y$, Oda $M$. Corricobasal degeneration: a disease with widespread appearance of abnormal tau and neurofibrillary tangles, and its relation to progressive supranuclear palsy. Acta Neuropathol (Berl) 1994;88:113-121

19. Petersen RB, Tabaton $M$, Chen $S G$, et al. Familial progressive subcortical gliosis: presence of prions and linkage to chromosome 17. Neurology 1995;45:1062-1067

20. Gaughran F, Keohane C, Buckley M. Familial dementia with Pick cells. A case report of probable Pick's disease. Ir J Psychol Med 1994;11:34-38 
21. Lynch T, Sano M, Marder KS, et al. Clinical characteristics of a family with chromosome 17-linked disinhibition-dementiaparkinsonism-amyotrophy complex. Neurology 1994;44:18781884

22. Sima AAF, Defendini RF, Keohane $C$, et al. The neuroparhology of chromosome 17-linked dementia. Ann Neurol 1996;39: $734-744$

23. Cordes M, Wszolek ZK, Pfeiffer RF, Calne DB. Examination of the presynaptic dopaminergic system using positron emission tomography in a family with aurosomal dominant parkinsonism and dementia due to pallido-ponto-nigral degeneration (PPNO). Radiol Diagn (Berl) 1993;34:141-145

24. Cordes M, Wszolek ZK, Calne DB, et al. Magnetic resonance imaging studies in rapidly progressive autosomal dominant parkinsonism and dementia with pallido-ponto-nigral degeneration. Neurodegeneration 1992;1:217-224

25. Denson MA, Wszolek ZK. Familial parkinsonism: our experience and review. Parkinsonism Relat Dis 1995;1:35-46

26. Wijker M, Wszolek ZK, Wolters ECH, et al. Localization of the gene for rapidly progressive autosomal dominant parkinsonism and dementia with pallido-ponto-nigral degeneration to chromosome 17q21. Hum Mol Genet 1996;5:151-154

27. Wszolek ZK, Pfeiffer RF. Rapidly progressive autosomal dominant parkinsonism and dementia with pallido-ponto-nigral degeneration. In: Stern MB, Koller WC, eds. Parkinsonian syndromes. New York: Marcel Dekker, 1993:297-312

28. Wszolek ZK, Pfeiffer RF, Bhatt $M H$, et al. Rapidly progressive autosomal dominant parkinsonism and dementia with pallidoponto-nigral degeneration. Ann Neurol 1992;32:312-320

29. Yamada T, McGeer EG, Schelper RL, et al. Histological and biochemical pathology in a family with autosomal dominant parkinsonism and dementia. Neurol Psychiat Brain Res 1993; 2:26-35

30. Sumi SM, Bird TD, Nochlin D, Raskind MA. Familial presenile dementia with psychosis associated with cortical neurofi- brillary tangles and degeneration of the amygdala. Neurology $1992 ; 42: 120-127$

31. Spillantini MG, Crowther RA, Goedert M. Comparison of the neurofibrillary pathology in Alzheimer's disease and familial presenile dementia with tangles. Acta Neuropathol 1996;92: $42-48$

32. Heutink P, Stevens M, Rizzu P, et al. Hereditary frontotemporal dementia is linked to chromosome $17 \mathrm{q} 21-22$. A genetic and clinico-pathological study of three Dutch families. Ann Neurol 1997;41:150-159

33. Yamaoka LH, Welsh-Bohmer KA, Hulette CM, et al. Linkage of frontotemporal dementia to chromosome 17: clinical and neuropathological characterization of phenotype. Am J Hum Genet 1996;56:1306-1312

34. Lendon CL, Shears S, Busfield $F$, et al. Molecular genetics of hereditary dysphasic dementia. Neurobiol Aging 1994;15(suppl 1):S128 (abstract)

35. Dark F. A family with autosomal dominant, non-Alzheimer's presenile dementia. Aust NZ J Psychiatry (In press)

36. Hutton $M$, Baker $M$, Houlden $H$, et al. Genetic analysis of an Australian pedigree with autosomal dominant non-Alzheimer's dementia. Am J Hum Genet 1996;59(suppl):A221 (abstract)

37. Sanders J, Schenk VWD, van Veen P. A family with Pick's disease. Verh K Nederland Akad Wetensch 1939; section 2, part 38 , no. 3

38. Schenk VWD. Re-examination of a family with Pick's disease. Ann Hum Genet 1959;23:325-333

39. Stevens $M$, van Swieten JC, van Duijn CM, et al. Familiaire vormen van frontotemporale dementie. (Familial forms of fronto-temporal dementia.) Ned Tijdschr Genceskd 1995;139: $871-875$

40. Verhaart WJC. Over de ziekte van Pick. Ned Tijdschr Geneeskd 1930;74:5586-5598

41. Lanska DJ, Currier RD, Cohen $M$, et al. Familial progressive subcortical gliosis. Neurology 1994;44:1633-1643 